\title{
Nutrient amendment does not increase mineralisation of sequestered carbon during incubation of a nitrogen limited mangrove soil
}

Joost A. Keuskamp ${ }^{\mathrm{a}, *}$, Heike Schmitt ${ }^{\mathrm{b}}$, Hendrikus J. Laanbroek ${ }^{\mathrm{a}, \mathrm{c}}$, Jos T.A. Verhoeven $^{\mathrm{a}}$, Mariet M. Hefting ${ }^{\mathrm{a}}$

${ }^{a}$ Institute of Environmental Biology, Utrecht University, PO Box 80084, 3508 TB, Utrecht, The Netherlands

${ }^{b}$ Institute for Risk Assessment Sciences, Utrecht University, Utrecht, The Netherlands ${ }^{c}$ Department of Microbial Wetland Ecology Netherlands Institute of Ecology

(NIOO-KNAW), Wageningen, The Netherlands

\section{Abstract}

Mangrove forests are sites of intense carbon and nutrient cycling, which result in soil carbon sequestration on a global scale. Currently, mangrove forests receive increasing quantities of exogenous nutrients due to coastal development. The present paper quantifies the effects of nutrient loading on microbial growth rates and the mineralisation of soil organic carbon (SOC) in two mangrove soils contrasting in carbon content. An increase in SOC mineralisation rates would lead to the loss of historically sequestered carbon and an enhanced $\mathrm{CO}_{2}$ release from these mangrove soils.

In an incubation experiment we enriched soils from Avicennia and Rhizophora mangrove forests bordering the Red Sea with different combinations of nitrogen, phosphorus and glucose to mimic the effects of wastewater influx. We measured microbial growth rates as well as carbon mineralisation

\footnotetext{
*Corresponding author

Email address: j.a.keuskamp@uu.nl (Joost A. Keuskamp)
} 
rates in the natural situation and after enrichment. The results show that microbial growth is energy limited in both soils, with nitrogen as a secondary limitation. Nitrogen amendment increased the rate at which labile organic carbon was decomposed, while it decreased SOC mineralisation rates. Such an inhibitory effect on SOC mineralisation was not found for phosphorus enrichment.

Our data confirm the negative effect of nitrogen enrichment on the mineralisation of recalcitrant carbon compounds found in other systems. Based on our results it is not to be expected that nutrient enrichment by itself will cause degradation of historically sequestered soil organic carbon in nitrogen limited mangrove forests.

Keywords:

Avicennia, Rhizophora, mangrove, fertilisation, microbial activity, SOC, nitrogen mining, decomposition, SIR, Saudi Arabia

\section{1. Introduction}

2 Mangroves are highly productive ecosystems, growing at the interface of 3 land and sea along much of the tropical and subtropical coastlines, estuaries 4 and river mouths. Their position between land and sea makes them critical 5 in land-sea nutrient exchange. Due to their high primary productivity and 6 biological activity they can be considered a hotspot for nutrient and carbon 7 cycling so that changes in their functioning will have a substantial influence 8 on coastal nutrient and carbon dynamics. 
Mangrove soils are a large sink for carbon with estimated average carbon burial rates three to ten times higher than those of northern peatlands (Duarte et al., 2005; Bouillon et al., 2008; Limpens et al., 2008). Soil carbon content varies in mangroves, but many mangroves are peat-forming with peat layers up to several meters thick (Middleton and McKee, 2001; McKee et al., 2007) therefore containing significant amounts of carbon per unit of area.

During the past decades, nutrient influx to coastal systems has been increasing due to anthropogenic activity and could be considered a component of global change (Duarte, 2009; Nixon, 2009). These nutrient influxes affect several major processes in the mangrove carbon cycle, amongst which mangrove growth (Feller, 1995), peat build-up (McKee et al., 2007), and decomposition of leaf (Feller et al., 1999) and root litter(Huxham et al., 2010). Soil organic carbon (SOC) decomposition is potentially enhanced, changing mangroves from a carbon sink to a carbon source, especially if large amounts of historically sequestered carbon are mineralised. In peat-forming mangroves, this ultimately causes the system to collapse through elevational loss resulting in increasing inundation times and dieback of mangrove trees.

Nitrogen $(\mathrm{N})$ and phosphorus $(\mathrm{P})$ are the major limiting nutrients for mangrove tree growth (Reef et al., 2010) and their inflow rates to coastal waters have dramatically increased over the past decades (Seitzinger et al., 2010). The other macronutrients - potassium, calcium, magnesium and sulphur - are less likely to be limiting in a marine environment, as they are major constituents of seawater. We will therefore focus on nitrogen and phosphorus enrichment as a potentially moderating factor on SOC decomposition rates.

Additions of nitrogen and phosphorus stimulate plant growth if either of 
these are limiting. Likewise, nitrogen and phosphorus additions can be expected to stimulate decomposition when either of these elements is limiting microbial activity. Feller et al. (1999) indeed found enhanced litter decomposition after $\mathrm{P}$ addition in a $\mathrm{P}$-limited mangrove. The effect of nitrogen on decomposition rate is however rather complex, since SOC mineralisation has been shown to be either increased, unaffected or decreased by addition of N. Many studies have revealed that decomposition of recalcitrant litter (Knorr et al., 2005; Berg and Laskowski, 2006) and SOC (Neff et al., 2002) is inhibited by external nitrogen addition, while the decay of easily degradable litter or labile organic carbon (LOC) is stimulated, as also predicted by the nitrogen-mining theory (Moorhead and Sinsabaugh, 2006; Craine et al., 2007). The net effect on total SOC is not always clear: Mack et al. (2004) have demonstrated that long-term fertilisation in a tundra peatland leads to a dramatic loss of soil carbon through increased SOC decomposition rates while Shaver et al. (2006) find lower respiration rates in the same plots.

To our knowledge, the direct effects of nutrient and LOC addition on microbial growth and mineralisation rates in mangrove ecosystems have not been elucidated yet. In our research we assessed the effects on microbial growth and activity by measuring microbial respiration rates in soils from two common mangrove genera Avicennia and Rhizophora after amendments of nutrients and glucose. We expect that nitrogen addition increases microbial growth rate and LOC mineralisation in both genera, but that overall microbial activity is lower in the Rhizophora soil due high content of tannins, known to inhibit decomposition (Robertson, 1988).

The effect of nutrient additions on SOC mineralisation rates was studied 
more detailed in the Avicennia soil by measuring change in microbial biomass and respiration upon nitrogen, phosphorus,and glucose amendment. Here we expect that the amended nutrients differentially modify LOC and SOC decomposition rates: nitrogen as well as phosphorus addition will stimulate decomposition of LOC, while nitrogen but not phosphorus will inhibit SOC mineralisation.

\section{Material and Methods}

\subsection{Study site features}

The soils used for incubation were collected from mangrove stands dominated by either Avicennia marina or Rhizophora mucronata on Saudi Arabian islands in the Red Sea. The sampled Avicennia site was located on a small island just outside the campus of the King Abdullah University of Science and Technology (KAUST), near the village of Thuwal, Jeddah. The Avicennia covering the island varied in height, with tree sizes from $\pm 0.5 \mathrm{~m}$ in the dwarf zone up to $5 \mathrm{~m}$ in the fringe. The soil cores were taken in the western part of the island $\left(22^{\circ} 19^{\prime} 52^{\prime \prime} \mathrm{N}, 39^{\circ} 05^{\prime} 59^{\prime \prime} \mathrm{E}\right)$ where tidal floods could freely enter. In this area, trees had an average height of $3.5 \mathrm{~m}$.

The Rhizophora site was located at the Farazan Islands, an archipelago of coral islands in the southernmost part of Saudi Arabia. This group of islands probably supports the largest population of Rhizophora in the Red Sea (El-Demerdash, 1996). The soils were taken at the north-eastern part of Farazan Kebir, the largest of the Farazan Islands, at $16^{\circ} 47^{\prime} 24^{\prime \prime} \mathrm{N}, 42^{\circ} 05^{\prime} 59^{\prime \prime} \mathrm{E}$. This site was protected from high-energy waves by a number of land-tongues. Average tree height in this stand was similar to that of the Avicennia site. 


\subsection{Soil collection and analysis}

Within each study site, nine sampling locations were selected to account for small-scale variation. Soils were classified using the WRB soil classification system (IUSS Working Group WRB, 2007). At each location, eight $10 \mathrm{~cm}$ soil samples were taken using a stainless steel soil corer with a diameter of $9.6 \mathrm{~cm}$. Directly after sampling, redox conditions were measured at $5 \mathrm{~cm}$ from the top of the core using a Sentix PtR electrode (WTW GmbH, Weilheim, Germany). Pore water was sampled using $10 \mathrm{~cm}$ long Rhizon soil moisture samplers (Eijkelkamp BV, Giesbeek, the Netherlands). On the day of sampling, pore water $\mathrm{pH}$ was measured using a Sentix $41 \mathrm{pH}$ electrode (WTW GmbH, Weilheim, Germany) and salinity was determined using an optical refractometer with automatic temperature correction. Pore water and soil samples were sent to the Utrecht University, The Netherlands, and stored at $4^{\circ} \mathrm{C}$ until further analysis and incubation. The Rhizophora soils were sampled in November 2009; the Avicennia soils were sampled one year later in November 2010. Incubations started within five weeks after sampling. Bulk density of the soil was calculated from the core weight and volume of the corer. It does therefore include the effect of crab holes and other tertiary structures. Soil moisture content was determined by weight loss after a $48 \mathrm{~h}$ drying period at $70^{\circ} \mathrm{C}$. C/N ratios were determined using an EA/110 CHNS-O analyser (Interscience BV, Breda, The Netherlands). In preparation for the $\mathrm{C} / \mathrm{N}$ determination soils were homogenised and ground using an MM200 mixer mill (Retsch GmbH, Haan, Germany) at 20 RPS during two minutes. After grinding, the soils were washed with a $32 \% \mathrm{HCl}$ solution to remove $\mathrm{CaCO}_{3}$ and dried for $48 \mathrm{~h}$ at $70{ }^{\circ} \mathrm{C}$ to evaporate excess $\mathrm{HCl}$. Measured 
$\mathrm{C}$ and $\mathrm{N}$ concentrations were corrected for weight changes due to the $\mathrm{HCl}$ washing. Pore water was analysed for $\mathrm{PO}_{4}^{-}, \mathrm{NH}_{4}^{+}, \mathrm{NO}_{3}^{-}$, dissolved organic nitrogen (DON) and dissolved organic carbon DOC using a continuous flow auto analyser (Skalar SA-40, Breda, The Netherlands).

\subsection{Incubation experiment}

As mangrove soils are oxygenated with fresh air when the tide lowers, while mangrove roots oxygenate their surroundings during high tides, incubations were conducted in atmospheric circumstances as we believe this most closely matches the prevalent conditions in the sampled top layer. Before incubation, soils were allowed to drain with gravitation to mimic field conditions just after a flooding event. Collected soils were incubated to measure Substrate Induced Respiration (SIR) after Anderson and Domsch (1978) and subsequent growth respiration to calculate microbial growth rates. Respiration was measured after amendment with different combinations of glucose, ammonium, and phosphorus to alleviate energy and/or nutrient limitations. Soil samples of both Avicennia and Rhizophora stands were subjected to five treatments: Control, glucose (C), glucose plus ammonium (CN), glucose plus phosphorus (CP), and glucose plus ammonium plus phosphorus (CNP). The Avicennia soil additionally received an ammonium plus phosphorus (NP) treatment, without glucose. In preparation for the incubations, soil cores were manually cleared from roots and shells and homogenised. The homogenised soil was allowed to acclimatise for three days at $20^{\circ} \mathrm{C}$ in a dark box covered with a moist cloth to minimise evaporation from the soil.

To start the incubations, $0.1 \mathrm{ml}$ treatment solution per gram soil fresh weight (FW) was thoroughly mixed through the soil and $10 \mathrm{~g}$ of the amended 
soil was put in $600 \mathrm{ml}$ flasks. $\mathrm{D}^{+}$glucose was added as a source of labile organic carbon in the $\mathrm{C}$ treatment $\left(0.6 \mathrm{mg} \mathrm{Cg}\right.$ soil $\left.\mathrm{FW}^{-1}\right)$. In the $\mathrm{CNP}$ treatment, an equal amount of carbon was added together with $0.06 \mathrm{mg}$ g soil $\mathrm{FW}^{-1}$ nitrogen $\left(\right.$ as $\mathrm{NH}_{4} \mathrm{Cl}$ ) and $12 \mu \mathrm{g}$ g soil $\mathrm{FW}^{-1}$ phosphorus (as $\mathrm{Na}_{3} \mathrm{HPO}_{4}$ ). Relative molar amounts of $\mathrm{C}, \mathrm{N}$ and $\mathrm{P}$ were similar to that of aquatic microbial biomass $(C: N: P=50: 10: 1$, Fagerbakke et al. (1996)) to ensure that microbial nutrient limitation was released. After amendment, soils were incubated for 6 days at $20^{\circ} \mathrm{C}$. During incubation, $\mathrm{CO}_{2}$ production was measured at intervals of 130 minutes using a respirometer (Biometric Systems, Germany) equipped with optical $\mathrm{CO}_{2}$ and $\mathrm{O}_{2}$ sensors. The incubation flasks were flushed with fresh air whenever $\mathrm{CO}_{2}$ levels exceeded $4.5 \mathrm{mll}^{-1}$ or $\mathrm{O}_{2}$ levels decreased to less then $180 \mathrm{mll}^{-1}$

Additional to these treatments, we also incubated the above-mentioned treatments with $7.5 \mathrm{mmolg}$ soil $\mathrm{FW}^{-1}$ commercially available tannic acid to mimic the soluble tannin concentration of mangrove soils as reported by Alongi (1987), in order to assess whether these inhibit microbial activity.

\subsection{Fumigation-extraction}

In order to determine microbial biomass, $10 \mathrm{~g}$ of soil was subjected to a fumigation-extraction procedure according to Vance et al. (1987). We followed this procedure at the start and after $56 \mathrm{~h}$ of the incubation. In short, the procedure consisted of a $24 \mathrm{~h}$ treatment with an ethanol-free chloroform atmosphere followed by extraction with $50 \mathrm{~mL}$ of a $0.5 \mathrm{M} \mathrm{K}_{2} \mathrm{SO}_{4}$ solution.

After the extraction, DOC and DON concentrations were measured in fumigated and non-fumigated control soils using a continuous flow auto analyser (Skalar SA-40, Breda, The Netherlands). Following Vance et al. (1987), 
microbial carbon was estimated by multiplying the amount of DOC liberated by fumigation by an empirically derived factor of 2.64 reflecting the relative amount of non-extractable to extractable carbon in microbial biomass. DON was also measured to quantify nitrogen fluxes and calculate $\mathrm{C} / \mathrm{N}$ ratios of microorganisms. Following Brookes et al. (1985), we calculated microbial N as the difference in extractable DON before and after fumigation divided by 0.54. Only the Avicennia soils were subjected to the fumigation-extraction procedure as the necessary resampling for the Rhizophora soil was not logistically possible.

\subsection{Data analysis \& Statistics}

$\mathrm{CO}_{2}$ production rates increased exponentially after amendment. The rate of exponential increase was quantified using a logarithmic growth function (Simkins and Alexander, 1984), by fitting the initial, rising part of the respiration peak to an exponential growth function $R_{\mathrm{CO}_{2}}(t)$ analogous to Colores et al. (1996):

$$
R_{\mathrm{CO}_{2}}(t)=p \cdot e^{\mu_{\max }(t-b)}
$$

with $p$ being the initial respiration rate, $b$ the delay (i.e. lag time) before exponential growth starts and $\mu_{\max }$ the relative growth rate. The fitting was done using a least squares fitting procedure in Mathematica 7.0.0 (Wolfram research, Champaign (IL), USA). For each plot, the initial respiration rate $p$ was determined by first fitting the $\mathrm{CO}_{2}$ respiration rate of the control treatment to a negative value for specific growth rate $\mu_{\max }$; the value found for $p$ then was used as a fixed parameter in the fitting procedure for the amended samples originating from the same plot. 
Other values used for further analysis were obtained from directly measured respiration rates or cumulative respiration as calculated by integrating respiration rates to time. Initial microbial biomass carbon $\left(C_{m i c r}\right)$ was determined following the relationship given by Anderson and Domsch (1978) recalculated to standard units:

$$
C_{\text {micr }}=81.84 \cdot R_{C}+3.7
$$

with $C_{\text {micr }}$ in $\mu \mathrm{g}$ microbial $\mathrm{C}$ per $\mathrm{g}$ soil DW, and $R_{C}$ the average carbon respiration over the first 4 hours in $\mu \mathrm{g} g \mathrm{CO}_{2}-\mathrm{Ch}^{-1} \mathrm{~g}$ soil DW. We measured basal respiration $(B R)$ as an averaged respiration rate in soils without amendment over the first $24 \mathrm{~h}$ after the pre-incubation. The metabolic quotient $\left(\mathrm{q}_{\mathrm{CO}_{2}}\right)$, i.e. the relative respiration rate for microorganisms, was calculated as $B R / C_{m i c r}$ (Anderson and Domsch, 1985). Respiration quotient $q_{C}$, the amount of carbon respired per unit available SOC, was calculated as BR/SOC content (Anderson and Domsch, 1986). Microbial respiratory quotient $R Q$ was measured as $\mathrm{CO}_{2} / \mathrm{O}_{2}$ in $\mathrm{mol} \mathrm{mol}^{-1}$ (Dilly, 2001) for both amended and unamended soils.

All data were analysed using $\mathrm{R}$ version 2.12.1 (R Development Core Team, 2010). Some outliers occurred in the fumigation procedure and short-term $\mathrm{CO}_{2}$ measurements. These were identified manually and removed upon confirmation by Grubbs test. Homogeneity of variances was confirmed using Levene's test. Normality was tested with the Shapiro-Wilk test. Treatment effects were tested using an ANOVA on a linear model with replicate as a random factor to account for soil heterogeneity. Post-hoc testing for group differences was done with Tukey HSD for group differences where applicable. Differences between two groups were judged using Welch's t-test in case of 
normal distributions. The Mann-Whitney U test was used for group differences between non-parametric data such as redox conditions and temperature in Table 1. Experimental data were tested on measured values per unit fresh weight (FW) rather than units dry weight as we performed all experiments keeping units fresh weight equal between treatments. Values after \pm indicate standard error.

\section{Results}

\subsection{Edaphic properties and initial nutrient status}

The Avicennia marina and the Rhizophora mucronata derived soils were comparable with respect to $\mathrm{pH}$, redox, temperature and salinity (Table 1).The black Rhizophora soil was a moderately organic silt loam, while the Avicennia soil consisted of coarse calcareous sand and contained little organic material. The difference between the soils was also reflected in the lower bulk density and nutrient content of the Avicennia derived soil. The pore water phosphorus and ammonium concentrations were three to eight times higher in the Rhizophora soil as compared to the Avicennia soil, as were the soil organic carbon and nitrogen contents. The N:P ratio in the pore water of Avicennia was 26, that of Rhizophora 12. In both the Rhizophora and Avicennia systems, surface water nutrient concentrations (Rhizophora : $\mathrm{NO}_{3}:<0.02 \mathrm{mgl}^{-1}$; $\mathrm{NH}_{4}: 0.1 \mathrm{mgl}^{-1} ; \mathrm{PO}_{4}: 0.1 \mathrm{mgl}^{-1}$, Avicennia : $\mathrm{NO}_{3}, \mathrm{NH}_{4}$, and $\mathrm{PO}_{4}:<$ $0.02 \mathrm{mg} \mathrm{l}^{-1}$ ) were lower than those of pore water (Table 1). Moisture content at the time of incubation was close to field capacity with $0.32 \pm 0.01 \mathrm{~g} \mathrm{~g}^{-1}$ and $0.60 \pm 0.03 \mathrm{~g} \mathrm{~g}^{-1}$ for the Avicennia and the Rhizophora soil respectively. 
Table 1: Edaphic and other site-specific properties as measured at two mangrove stands in Saudi Arabia ( $\mathrm{N}=9$ ). Significant (quantitative) differences between sites are indicated in the first column $\left({ }^{*} \mathrm{p}<0.05,{ }^{* *} \mathrm{p}<0.01\right.$ and $\left.{ }^{* * *} \mathrm{p}<0.001\right)$. Numbers after \pm indicate standard errors.

\begin{tabular}{|c|c|c|c|}
\hline Property & Avicennia & Rhizophora & Unit \\
\hline location & Thuwal (SA) & Farazan (SA) & \\
\hline \multirow{2}{*}{ soil type } & Tidalic Gleyic & Tidalic Mollic & \\
\hline & Solonchaks & Fluvisol (magniferric) & \\
\hline texture & Sand & Silt & \\
\hline tree height & $3-4$ & $3-4$ & $\mathrm{~m}$ \\
\hline $\mathrm{pH}$ & $6.9 \pm .1$ & $7.0 \pm .1$ & - \\
\hline salinity* & $50 \pm 0$ & $46 \pm 1$ & $\operatorname{mg~g}^{-1}$ \\
\hline redox* & $69 \pm 53$ & $-22 \pm 20$ & $\mathrm{mV}$ \\
\hline temperature* & $30.3 \pm .2$ & $32.9 \pm .4$ & ${ }^{\circ} \mathrm{C}$ \\
\hline bulk density* & $1.15 \pm .11$ & $.50 \pm .3$ & $\mathrm{~g}$ soil $\mathrm{DW} \mathrm{cm}^{-3}$ \\
\hline $\mathrm{SOC}^{* * *}$ & $18 \pm 2$ & $79 \pm 6$ & mg g soil $\mathrm{DW}^{-1}$ \\
\hline $\mathrm{SON}^{* * *}$ & $1.4 \pm .1$ & $4.7 \pm .2$ & mg g soil $\mathrm{DW}^{-1}$ \\
\hline DOC & $32 \pm 3$ & $27 \pm 1$ & $\mathrm{mg} \mathrm{l}^{-1}$ \\
\hline DON & $<.2$ & $<.2$ & $\mathrm{mg} \mathrm{l}^{-1}$ \\
\hline $\mathrm{NO}_{3}^{-}$ & $<1$ & $<1$ & $\mu \mathrm{mol} \mathrm{l}^{-1}$ \\
\hline $\mathrm{NH}_{4}^{+* *}$ & $13 \pm 3$ & $49 \pm 9$ & $\mu \mathrm{mol} \mathrm{l}^{-1}$ \\
\hline $\mathrm{PO}_{4}^{3-* *}$ & $.5 \pm .2$ & $4 \pm 1$ & $\mu \mathrm{mol} \mathrm{l}^{-1}$ \\
\hline
\end{tabular}

SOC: Soil Organic Carbon, DOC: Dissolved Organic Carbon SON: Soil

Organic Nitrogen, DON: Dissolved organic nitrogen 


\subsection{Initial microbial biomass and activity}

To compare microbial activity between the soils from the Avicennia and Rhizophora sites at the start of the incubations, we determined microbial biomass $\left(C_{m i c r}\right)$, microbial respiration rate $(B R)$, and metabolic quotient $\left(q_{\mathrm{CO}_{2}}\right)$ (Table 2). Microbial respiration and SIR estimated microbial biomass per gram soil were markedly higher for the Rhizophora than for the Avicennia soil (BR: $\left.\mathrm{df}=6.7, \mathrm{p}<0.001, C_{m i c r}: \mathrm{df}=5.1, \mathrm{p}<0.05\right)$; note that these differences are not significant when expressed per unit volume. The respiration per unit carbon in the soil $\left(q_{C}\right)$ was significantly lower for the more organic Rhizophora soil $(\mathrm{df}=5.6, \mathrm{p}<0.005)$, whereas microbial respiratory quotient $(R Q)$ was for both soil types well below 1, which is the $R Q$ expected for aerobic consumption of reduced carbon substrates without growth (Dilly, 2003).

\subsection{Respiration response to glucose and nutrient amendments}

Glucose additions induced a clear respiration peak between 10 and $40 \mathrm{~h}$ after amendment (Figure 1: all treatments except Control and NP). The induced peak initially follows a curve similar to that for logistic growth, with an initial exponential growth phase followed by an exponential decrease of the specific growth rate to zero. This first exponential phase showed a good fit to the exponential growth rate function (eq. $1, R^{2}>0.98$ ). $\mu_{\max }$, the microbial specific growth rate in this equation describes change in time and hence has unit $\mathrm{h}^{-1}$. Unlike absolute measures such as respiration rate, $\mu_{\max }$ is suitable to compare microbial growth rates between systems as it does not depend on weight or volume units and is therefore insensitive to differences in moisture content or bulk mass. Overall, $\mu_{\max }$ is higher in Avicennia than in Rhizophora soil $(\mathrm{F}=67.0, \mathrm{p}<0.001)$ (Figure 2a; Table 3). Because there was 
Table 2: Microbial characteristics as measured in soils from two mangrove sites in the Red Sea dominated by either Avicennia marina or Rhizophora mucronata. Significant differences between sites are indicated in the first column $\left({ }^{*} \mathrm{p}<0.05,{ }^{* * *} \mathrm{p}<0.001\right)$. Numbers after \pm indicate standard errors.

\begin{tabular}{|c|c|c|c|}
\hline Property & Avicennia & Rhizophora & Unit \\
\hline$B R^{* * *}$ & $1.7 \pm .1$ & $4.0 \pm .3$ & $\mu g \mathrm{CO}_{2}-\mathrm{Cg}$ soil $\mathrm{DW}^{-1} \mathrm{~h}^{-1}$ \\
\hline$C_{m i c r}^{*}$ & $228 \pm 54$ & $559 \pm 95$ & $\mu \mathrm{g} C_{m i c} \mathrm{~g}$ soil $\mathrm{DW}^{-1}$ \\
\hline$q_{\mathrm{CO}_{2}}$ & $8 \pm 2$ & $9 \pm 1$ & $\operatorname{mg~} \mathrm{CO}_{2}-\mathrm{Ch}^{-1} \mathrm{~g} C_{m i c}^{-1}$ \\
\hline$C_{m i c}: C_{o r g}$ & $12 \pm 4$ & $7 \pm 1$ & $\operatorname{mg} C_{m i c} \mathrm{~g} \mathrm{SOC}^{-1}$ \\
\hline$q_{C}^{*}$ & $104 \pm 16$ & $52 \pm 4$ & $\mathrm{mg} \mathrm{CO}{ }_{2}-\mathrm{Ch}^{-1} \mathrm{~g} \mathrm{SOC}^{-1}$ \\
\hline$R Q$ & $.49 \pm .05$ & $.47 \pm .04$ & $\mathrm{~mol} \mathrm{CO} \mathrm{mol} \mathrm{O}_{2}^{-1}$ \\
\hline
\end{tabular}


Table 3: Experimental results of an incubation of soils from monospecific Avicennia marina and Rhizophora mucronata mangrove stands. Results are obtained during $150 \mathrm{~h}$ of incubation. The treatment consisted of a glucose addition $\left(0.05 \mathrm{mmol} \mathrm{Cg}\right.$ soil $\left.\mathrm{FW}^{-1}\right)$, with or without nitrogen $(\mathrm{N})$ or phosphorus $(\mathrm{P})$. Relative amounts of C:N:P were 50:10:1. Both soil types were analysed separately by ANOVA with treatment as a fixed factor, significant differences are indicated by letters. For $\mu_{\max }$ all differences indicated are significant at $\mathrm{p}<0.001$, for $R_{\text {cum }}$ this is $\mathrm{p}<0.01$.

\begin{tabular}{|c|c|c|c|}
\hline Species & Treatment & $\mu_{\max }$ & $R_{\text {cum }}$ \\
\hline Avicennia & Control & $-.005 \pm .000^{\mathrm{a}}$ & $.18 \pm .01 \quad \mathrm{a}$ \\
\hline \multirow[t]{5}{*}{ marina } & $\mathrm{NP}$ & $-.005 \pm 001^{\mathrm{a}}$ & $.18 \pm .01 \quad \mathrm{a}$ \\
\hline & $\mathrm{C}$ & $1.2 \pm .01 \quad \mathrm{~b}$ & $.61 \pm .06 \quad \mathrm{~b}$ \\
\hline & $\mathrm{CP}$ & $1.3 \pm .01 \quad \mathrm{~b}$ & $.70 \pm .03$ \\
\hline & $\mathrm{CN}$ & $2.6 \pm .02^{\mathrm{c}}$ & $.59 \pm .03$ \\
\hline & CNP & $3.8 \pm .01 \quad \mathrm{~d}$ & $.63 \pm .03 \quad \mathrm{~b}$ \\
\hline Rhizophora & Control & $-.088 \pm .004^{\mathrm{A}}$ & $.45 \pm .03 \quad \mathrm{~A}$ \\
\hline \multirow[t]{4}{*}{ mucronata } & $\mathrm{C}$ & $.6 \pm .1 \quad$ в & $1.15 \pm .07$ \\
\hline & $\mathrm{CP}$ & $.6 \pm .1 \quad$ в & $1.23 \pm .06$ \\
\hline & $\mathrm{CN}$ & $1.0 \pm .2 \quad$ в & $1.20 \pm .08$ \\
\hline & $\mathrm{CPN}$ & $2.8 \pm .3 \quad \mathrm{C}$ & $1.25 \pm .11$ \\
\hline
\end{tabular}


a significant interaction effect, we analysed the treatment effect separately for the two soil types.

In the Avicennia soil, we tested if nitrogen plus phosphorus (NP) application, without glucose addition, would induce a respiration peak, but this was not the case; in fact, like in the control treatment, respiration just followed a negative exponential curve after amendment (Fig 1: Control and NP treatments). Addition of both nitrogen and phosphorus together with glucose (CNP) increased $\mu_{\max }$ significantly compared to glucose only (C) treatments in both Avicennia and Rhizophora soil.

Lower stimulatory effects on glucose-induced growth were observed with single nutrient additions ( $\mathrm{N}$ or $\mathrm{P}$ ) in both soils: phosphorus plus glucose additions (CP) did not increase $\mu_{\max }$ as compared to the $\mathrm{C}$ treatment, while glucose plus nitrogen $(\mathrm{CN})$ addition only increased $\mu_{\max }$ in the Avicennia soil (Figure 2a; Table 3).

After the exponential growth phase, respiration rates come to a maximum rate $R_{\max }$ after which respiration declines again. $R_{\max }$ is equivalent to the inflection point of a logistic growth curve, where a limitation starts to reduce growth rates. The amount of $\mathrm{CO}_{2}$ produced at $R_{\max }$ was about one-third higher (df: 37.0, $\mathrm{p}<0.001$ ) in Rhizophora $\left(1.21 \mathrm{mg} \mathrm{CO}{ }_{2}-\mathrm{C} \pm 0.06 \mathrm{mg} \mathrm{CO}_{2}-\mathrm{C}\right.$ ) than in Avicennia with $0.83 \mathrm{mg} \mathrm{CO}_{2}-\mathrm{C} \pm 0.04 \mathrm{mg} \mathrm{CO}_{2}$-C, but did not differ significantly between nutrient treatments.

In the $\mathrm{CP}$ treatment, a second respiration peak occurs consistently in both Rhizophora and Avicennia derived soil, this second peak is small as compared to the first one, but similar in shape (Figure 1: CP). Such a second respiration peak is also observed in a number of Avicennia soil samples receiving the $\mathrm{C}$ 
treatment. The total respiration is elevated by glucose $(\mathrm{p}<0.001)$. Within the glucose treatments, $\mathrm{P}$ has a stimulatory effect on total respiration $(\mathrm{F}=7.3$, $\mathrm{p}<0.05)$.

The microbial respiratory quotient $(R Q)$ over 150 hours was significantly lower for Rhizophora in comparison to Avicennia soil in all treatments (Fig. $2 \mathrm{~b} ; \mathrm{F}=157.1, \mathrm{p}<0.001)$. In the control treatment, $R Q$ over the whole incubation was equal to initial values of $R Q$ in Rhizophora soil, but it almost doubled to $0.83 \pm 0.05$ for Avicennia soil. Glucose addition elevated $R Q$ significantly in both Avicennia $(\mathrm{F}=11.9, \mathrm{p}<0.01)$ and Rhizophora $(\mathrm{F}=75.0$, $\mathrm{p}<0.001)$ soil, but supplementary nitrogen or phosphorus amendment did not alter $R Q$ significantly (Figure $2 \mathrm{~b}$ ). Tannic acid addition slightly increased total respiration with $0.10 \mathrm{mg} \mathrm{CO}_{2}-\mathrm{Cg}$ soil $\mathrm{FW}^{-1} \pm 0.02 \mathrm{mg} \mathrm{CO}_{2}-\mathrm{Cg}$ soil $\mathrm{FW}^{-1}$ in both Avicennia and Rhizophora soil $(\mathrm{F}=28.3$, $\mathrm{p}<0.001)$, but did not modify $\mu_{\max }$ in any of the treatments (data not shown).

\subsection{Carbon and nitrogen budget}

We accounted for all net carbon fluxes during incubation by measuring changes in DOC, $C_{m i c r}$ and cumulative respiration losses over the incubation period (Figure 3a). Similarly, mineralisation of soil organic nitrogen can be quantified by measuring changes in nitrogen pools (Figure 3b) and correcting for nitrogen amendment where needed. We did not measure $\mathrm{N}_{2} \mathrm{O}$ and $\mathrm{N}_{2}$ efflux through denitrification, as earlier tests on these soils showed that gaseous nitrogen loss was negligible under the experimental conditions (data not shown). For both carbon and nitrogen the only unknown pool is soil organic matter, so that all changes in total pool can be attributed to either experimental addition or decomposition of soil organic matter. 
Table 4: Microbial response to carbon and nutrient amendments in soils from an Avicennia marina dominated system. Results are obtained after 80 hours of incubation at $20^{\circ} \mathrm{C}$ followed by fumigation-extraction. The treatments consisted glucose (C), nitrogen $(\mathrm{N})$ and phosphorus $(\mathrm{P})$ additions in various combinations. Glucose addition was $0.05 \mathrm{mmol} \mathrm{Cg}$ soil $\mathrm{FW}^{-1}$, relative amounts were 50:10:1 for C:N:P.

\begin{tabular}{|c|c|c|c|c|c|c|}
\hline treatment & $G_{\text {eff }}$ & $C_{m i c r}$ & $N_{m i c r}$ & $\mathrm{C} / \mathrm{N}$ & $S O C_{\min }$ & $S O N_{\min }$ \\
\hline Initial & - & $202 \pm 28$ & $17 \pm 2$ & $11 \pm 1$ & - & - \\
\hline Control & - & $174 \pm 51$ & $15 \pm 5$ & $14 \pm 5$ & $69 \pm 51$ & $-1 \pm 4$ \\
\hline NP & - & $216 \pm 6$ & $68 \pm 17$ & $3 \pm 1$ & $89 \pm 51$ & $5 \pm 16$ \\
\hline $\mathrm{C}$ & $.67 \pm 2$ & $621 \pm 27$ & $24 \pm 5$ & $22 \pm 4$ & $133 \pm 66$ & $6 \pm 3$ \\
\hline $\mathrm{CP}$ & $.49 \pm 5$ & $683 \pm 114$ & $37 \pm 9$ & $30 \pm 7$ & $233 \pm 143$ & $7 \pm 4$ \\
\hline $\mathrm{CN}$ & $.49 \pm 3$ & $617 \pm 69$ & $109 \pm 7$ & $6 \pm 1$ & $36 \pm 76$ & $34 \pm 8$ \\
\hline CNP & $.39 \pm 3$ & $508 \pm 52$ & $86 \pm 12$ & $6 \pm 1$ & $-28 \pm 69$ & $-3 \pm 11$ \\
\hline \multicolumn{7}{|c|}{ 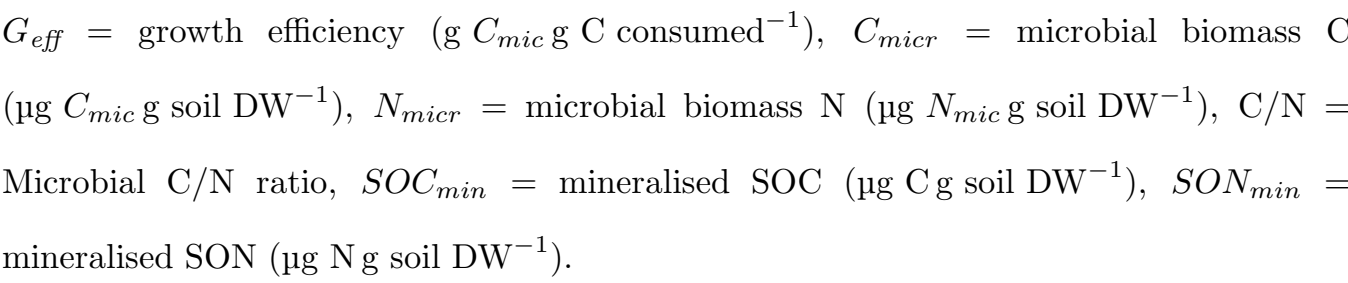 } \\
\hline
\end{tabular}


In the treatments where no glucose was added, $C_{\text {micr }}$ slightly decreased while DOC concentration remained the same. Respiration slightly exceeded the loss of microbial carbon so that a net SOC mineralisation was observed (Table 4). In the glucose-amended treatments (C, CP, CN, CNP), carbon fluxes were markedly higher as a result of the added glucose: $C_{m i c r}$ tripled and respiration almost quintupled. The DOC pool did not change during incubation with the exception of the $\mathrm{C}$ treatment where an increase in DOC indicated an incomplete consumption of the added glucose (Figure 3a). To calculate SOC decomposition in these treatments, the amended glucose-carbon was subtracted from the total flux. In Figure 3a this is graphically shown by the horizontal bar: the lower border of this bar represents the amendment of glucose-carbon, the height of the bar indicates the SOC mineralisation in the control treatment for comparison.

We tested the effects of carbon additions with a one-way ANOVA on the control and the glucose treatment. Within each carbon treatment we tested for the effect of nutrient addition with a two-way ANOVA with nitrogen and phosphorus as main effects. Since these two comparisons are orthogonal, ordinary F-tests without corrections were used. There were no significant effects of $\mathrm{P}$ or $\mathrm{C}$, but $\mathrm{N}$ did show a significant inhibition on SOC mineralisation $(\mathrm{F}=7.9, \mathrm{p}<0.05)$ in the glucose-amended treatments. In Figure 4 we summarised the effects of $\mathrm{C}$ and $\mathrm{N}$ on LOC and SOC decomposition.

Growth efficiency $\left(G_{\text {eff }}\right)$ (microbial C/consumed C) indicates the amount of carbon needed to produce a certain amount of microbial biomass. Phosphorus and nitrogen additions additively lowered growth efficiencies (nitrogen: $\mathrm{F}=5.6, \mathrm{p}<0.05$, phosphorus: $\mathrm{F}=5.3, \mathrm{p}<0.05)$ so that the $\mathrm{C}$ treatment 
had the highest and the CNP treatment the lowest growth efficiency (Table 4).

The nitrogen budget in Figure 3b shows changes in dissolved and microbial nitrogen pools during the incubation. In the nitrogen amended treatments DON + DIN as well as microbial $\mathrm{N}$ are clearly elevated indicating partial consumption of the added N. The relative amount of immobilised nitrogen (microbial N/(DIN + DON $)$ ) was increased by glucose addition $(\mathrm{F}=5.2, \mathrm{p}<0.05)$. Microbial $\mathrm{C} / \mathrm{N}$ ratios in the control treatments did not change significantly during incubation. The microbial $\mathrm{C} / \mathrm{N}$ ratios in the other treatments were strongly determined by the ammonium and glucose additions and differed almost tenfold from 22-30 for samples receiving carbon without nitrogen to 3 for samples receiving nitrogen without carbon.

\section{Discussion}

\subsection{Basal nutrient status and microbial activity}

The microorganisms in the studied mangrove soils are primarily energylimited, even though a substantial amount of organic carbon is locked in the surrounding soil as SOC (Avicennia : 2\%, Rhizophora : 8\%). The high metabolic quotient $\left(q_{\mathrm{CO}_{2}}\right)$ reveals low energy use efficiency as compared to other terrestrial (Anderson and Domsch, 1993) or submerged soils (Torres et al., 2011). At the same time, heterotrophic activity in the Avicennia and Rhizophora dominated soils largely depends on the oxidation of refractory compounds as shown by low $R Q$ values (Dilly, 2001). We therefore hypothesize that the microbial community of the studied soils are severely energy 
stressed and largely composed of K-strategists: slowly growing microorganisms oxidising mainly recalcitrant materials.

Differences in soil carbon dynamics were found between the two mangrove genera, despite comparable edaphic properties. In the Rhizophora site, mineralisation rates are twice as high as compared to the Avicennia soil, while carbon storage is four times higher. Assuming that the carbon burial rate is in steady state at the moment of sampling, the input of carbon to the Rhizophora soil is therefore at least twice as high as encountered in the Avicennia dominated system. Relative carbon use $\left(q_{C}\right)$ and the microbial biomass per unit carbon, were lower in the Rhizophora derived soil. This translates to a higher average residence time of carbon in the Rhizophora as compared to the Avicennia soil, and therefore a higher recalcitrance of organic matter in the Rhizophora system. This finding is in accordance to what is generally found for litter of these genera (Robertson, 1988; Sessegolo and Lana, 1991; Middleton and McKee, 2001) and is often ascribed to the higher tannin and lower nitrogen content of Rhizophora litter. Due to the larger carbon pool and higher recalcitrance, priming effects of labile organic carbon and inhibition of nitrogen on SOC decomposition are suspected to be stronger in the Rhizophora site.

\subsection{Microbial growth rate, energy, and nutrient limitations}

The hypothesised energy limitation for heterotrophic microbial activity was confirmed in the incubation experiment as adding labile organic carbon (LOC) induced exponentially growing respiration rates, indicating microbial growth at a constant rate $\mu_{\max }$. Nitrogen addition only increased respiration rates when added in combination with LOC (in Avicennia) or in combination with 
LOC and phosphate (in Rhizophora). This is in accordance to what could have been expected based on pore water N:P ratios, when assuming a microbial N:P of 10 as estimated for aquatic microorganisms by Fagerbakke et al. (1996) or 6-16:1 by Vrede et al. (2002) for marine bacteria. In future assays it would be worthwhile to assess if pore water nutrient concentrations are a good predictor of nutrient limitation for heterotrophic growth.

In all treatments, including those with tannic acid amendment, a lower $\mu_{\max }$ and $R Q$ was found in the Rhizophora soil as compared to the Avicennia soil. This is not thought to be caused by differences in $\mathrm{LOC}$ or $\mathrm{O}_{2}$ availability between the two soils: $\mu_{\max }$ does not decline with respiration rate, indicating that carbon uptake rate is limited by uptake capacity and growth and not by LOC availability or diffusion rates. The $R Q$ is never larger than one, showing that decomposition was aerobic. As the lower $\mu_{\max }$ and $R Q$ found for $R h i$ zophora was independent of nutrient status or soluble tannin concentrations, the prevailing microbial communities must underlie this effect. The lower microbial growth rate found for Rhizophora indicates an even larger dominance of microbial K-strategists in these soils as compared to the Avicennia derived soil.

A priming effect, a long-term change in decomposition rate due to a onetime addition of a resource, could not be confirmed in any of the treatments, as microbial activity did not reach equilibrium and still declined towards the end of the incubation period of 180 hours. Nevertheless, from our glucoseamended treatments it is clear that, when sufficient energy is supplied, nitrogen addition increases microbial growth rates and LOC mineralisation in microbial communities of Avicennia and Rhizophora mangrove soils. Dur- 
ing continuous loading with LOC and nitrogen, which would be a realistic scenario for pollution by wastewater, we expect these dynamics to be the same. Whether this has consequences for the SOC pool was assessed for the Avicennia dominated soil where we measured changes in microbial biomass, DOC and $\mathrm{CO}_{2}$ efflux as well as soil nitrogen pool.

\subsection{Carbon and nitrogen budgets}

For the Avicennia derived soil, a carbon and nitrogen budget was constructed by measuring microbial consumption, growth and respiration. In the glucoseamended treatment not all glucose carbon was consumed, confirming that heterotrophic activity was not energy-limited after amendment. Strikingly, both nitrogen and phosphorus increased LOC use, while at the same time decreasing growth efficiencies. The decreased energy efficiency suggests increased synthesis of energy-rich substances. Possible mechanisms include the synthesis of polyphosphate to store energy (Kortstee et al., 1994) in the P-enriched soils and an increased internal enzyme production in the nitrogenenriched soils. A hint towards polyphosphate accumulation is the secondary peak in respiration consistently observed not only in Avicennia but also in Rhizophora derived soil after P addition (Fig. 1). This could be caused by delayed synthesis of polyphosphate as an energy store, but the results do not provide a definite answer as to which mechanisms are involved.

Added nitrogen was readily absorbed by microbial biomass, even in the absence of growth, and the soil microorganisms proved quite plastic with respect to their relative nitrogen content. Initially the microbial $\mathrm{C} / \mathrm{N}$ ratio was 11; after $\mathrm{N}$ addition, when carbon was limiting the $\mathrm{C} / \mathrm{N}$ ratio decreased to as low as 3. At that point the microbial $\mathrm{C} / \mathrm{N}$ ratio is as high as that of 
proteins, so that a higher $\mathrm{N}$ content is unlikely to occur (Fagerbakke et al., 1996). In the $\mathrm{C}$ and $\mathrm{CP}$ treatments, where nitrogen was made limiting, $\mathrm{C} / \mathrm{N}$ increased to 22-30, a value much higher than previously reported for marine bacteria (Vrede et al., 2002), indicating internal carbon storage as glycogen or some other polysaccharide.

While nitrogen in itself did not significantly stimulate or inhibit SOC decomposition in these systems, nitrogen amendment clearly inhibited SOC mineralisation when energy limitation was released. This finding is similar to that of Yamasaki et al. (2011) in a terrestrial forest and fits the nitrogenmining theory (Craine et al., 2007), which states that under nitrogen limitation, recalcitrant material is broken down to obtain nitrogen, even though this is energetically not favourable.

\subsection{Effects of nutrient enrichment on mangrove carbon sequestration}

The microbial communities of mangrove soils form a large sink for carbon, while enhancing nitrogen availability through decomposition of soil organic matter. At the same time, the microbial community forms a large sink for exogenous nitrogen and most likely also phosphorus when these are available in higher concentrations. The size of this sink increases as long as there is a concurrent input of labile organic carbon. Although nutrients stimulate growth of microorganisms and increase the mineralisation rates of labile organic carbon, soil organic matter decay is not stimulated. It is therefore not expected that increased nutrient exposure of the microbial communities in mangrove soils will deteriorate existing soil organic carbon pools in mangroves.

Even more so, as primary production in mangroves is nutrient-limited 
while decomposition is energy-limited, there is a differential limitation between carbon production and carbon decomposition. This suggests an increased carbon sequestration rate of mangrove forests upon exposure to nutrients. From preliminary results (data not shown) it is clear that such an increase in primary production upon nutrient enrichment takes place in the Avicennia site from our research. Mangroves have been proposed to be usable as wastewater polishing facilities by a number of authors (Wong et al., 1997; Tam et al., 2009). One could speculate that this could work without losing carbon sequestration capacity: the nitrogen supplied increases primary production thus increasing carbon input to the soil, while excess LOC is readily decomposed by microorganisms. The extra microbial activity does not lead to $\mathrm{CO}_{2}$ release from SOC decomposition as long as sufficient nitrogen is supplied.

Caution is required when extrapolating above conclusions up to the ecosystem scale, as soil-plant feedbacks were not included in this study. Reef et al. (2010) point out that nutrient enrichment potentially decreases primary production. In addition, increasing nutrient availability decreases tannin production (Lin et al., 2009) thereby potentially increasing decomposability. Moreover, relative root production also decreases with rising nutrient availability (Naidoo, 2009) while mangrove roots decompose slowly and are important in peat formation (Middleton and McKee, 2001). On the long term this may dramatically decrease the amount of sequestered carbon especially in mangroves depending on soil accretion through accumulation of dead root material. 


\section{5. Acknowledgements}

${ }_{476}$ We would like to thank Dr. Abdulazziz AlSuwailem, Dr. Zenon Batang, and 477 Dr. Nabeel Abdulaziz of the CMOR Lab for their help in the field and 478 Dr. Dennis Wigham and Dr. Ilka Feller at SERC for their ideas and sug479 gestions on site selection and sampling.

480 481 This publication was supported by Award No KUK-C1-017-12, made avail482 able by King Abdullah University of Science and Technology (KAUST), 483 Thuwal, Saudi Arabia. 
Alongi, D. M., 03 1987. The influence of mangrove-derived tannins on intertidal meiobenthos in tropical estuaries. Oecologia 71 (4), 537-540.

Anderson, J. P. E., Domsch, K. H., 1978. A physiological method for the quantitative measurement of microbial biomass in soils. Soil Biology and Biochemistry 10 (3), 215-221.

Anderson, T.-H., Domsch, K., 1985. Maintenance carbon requirements of actively-metabolizing microbial populations under in situ conditions. Soil Biology and Biochemistry 17 (2), $197-203$.

Anderson, T.-H., Domsch, K. H., 1986. Carbon link between microbial biomass and soil organic matter. In: Megusar, F., Gantar, M. (Eds.), Perspectives in Microbial Ecology. Slovene Society for Microbiology, Ljubljana, Yugoslavia, pp. 467-471.

Anderson, T.-H., Domsch, K. H., 1993. The metabolic quotient for $\mathrm{CO}_{2}$ $\left(\mathrm{qCO}_{2}\right)$ as a specific activity parameter to assess the effects of environmental conditions, such as ph, on the microbial biomass of forest soils. Soil Biology and Biochemistry 25 (3), 393-395.

Berg, B., Laskowski, R., 2006. Litter Decomposition: A guide to Carbon and Nutrient Turnover, 1st Edition. Academic Press, New York.

Bouillon, S., Borges, A. V., Castañeda-Moya, E., Diele, K., Dittmar, T., Duke, N. C., Kristensen, E., Lee, S. Y., Marchand, C., Middelburg, J. J., Rivera-Monroy, V. H., Smith, T. J., Twilley, R. R., 2008. Mangrove production and carbon sinks: A revision of global budget estimates. Global Biogeochemical Cycles 22 (2). 
Brookes, P. C., Landman, A., Pruden, G., Jenkinson, D. S., 1985. Chloroform fumigation and the release of soil nitrogen: A rapid direct extraction method to measure microbial biomass nitrogen in soil. Soil Biology and Biochemistry 17 (6), 837-842.

Colores, G. M., Schmidt, S. K., Fisk, M. C., 1996. Estimating the biomass of microbial functional groups using rates of growth-related soil respiration. Soil Biology and Biochemistry 28 (12), 1569-1577.

Craine, J. M., Morrow, C., Fierer, N., 2007. Microbial nitrogen limitation increases decomposition. Ecology 88 (8), 2105-2113.

Dilly, O., 2001. Microbial respiratory quotient during basal metabolism and after glucose amendment in soils and litter. Soil Biology and Biochemistry $33(1), 117-127$.

Dilly, O., 2003. Regulation of the respiratory quotient of soil microbiota by availability of nutrients. FEMS Microbiology Ecology 43 (3), 375-381.

Duarte, C., 2009. Coastal eutrophication research: A new awareness. Hydrobiologia 629 (1), 263-269.

Duarte, C. M., Middelburg, J. J., Caraco, N., 2005. Major role of marine vegetation on the oceanic carbon cycle. Biogeosciences 2 (1), 1-8.

El-Demerdash, M. A., 02 1996. The vegetation of the farasān islands, Red Sea, Saudi Arabia. Journal of Vegetation Science 7 (1), 81-88.

Fagerbakke, K. M., Heldal, M., Norland, S., 1996. Content of carbon, nitro- 
gen, oxygen, sulfur and phosphorus in native aquatic and cultured bacteria. Aquatic Microbial Ecology 10, 15-27.

Feller, I., Whigham, D., O’Neill, J., McKee, K., 1999. Effects of nutrient enrichment on within-stand cycling in a mangrove forest. Ecology 80 (7), $2193-2205$.

Feller, I. C., 1995. Effects of nutrient enrichment on growth and herbivory of dwarf red mangrove (Rhizophora mangle). Ecological Monographs 65 (4), $477-505$.

Huxham, M., Langat, J., Tamooh, F., Kennedy, H., Mencuccini, M., Skov, M. W., Kairo, J., 2010. Decomposition of mangrove roots: Effects of location, nutrients, species identity and mix in a Kenyan forest. Estuarine, Coastal and Shelf Science 88 (1), 135-142.

IUSS Working Group WRB, 2007. World reference base for soil resources 2006, first update 2007. World Soil Resources report No. 103. FAO, Rome.

Knorr, M., Frey, S. D., Curtis, P. S., 2005. Nitrogen additions and litter decomposition: a meta-analysis. Ecology 86 (12), 3252-3257.

Kortstee, G. J. J., Appeldoorn, K. J., Bonting, C. F. C., van Niel, E. W. J., van Veen, H. W., 10 1994. Biology of polyphosphate-accumulating bacteria involved in enhanced biological phosphorus removal. FEMS Microbiology Reviews 15 (2-3), 137-153.

Limpens, J., Berendse, F., Blodau, C., Canadell, J. G., Freeman, C., Holden, J., Roulet, N., Rydin, H., Schaepman-Strub, G., 05 2008. Peatlands and 
the carbon cycle: From local processes to global implications - a synthesis. Biogeosciences Discussions 5 (2), 1379-1419.

Lin, Y. M., Liu, X. W., Zhang, H., Fan, H. Q., Lin, G. H., 2009. Nutrient conservation strategies of a mangrove species Rhizophora stylosa under nutrient limitation. Plant and Soil 326 (1), 469-479.

Mack, M., Schuur, E., Bret-Harte, M., Shaver, G., Chapin III, F., 2004. Ecosystem carbon storage in arctic tundra reduce by long-term nutrient fertilization. Nature 431 (7007), 440-443.

McKee, K. L., Cahoon, D. R., Feller, I. C., 2007. Caribbean mangroves adjust to rising sea level through biotic controls on change in soil elevation. Global Ecology and Biogeography 16 (5), 545-556.

Middleton, B. A., McKee, K. L., 2001. Degradation of mangrove tissues and implications for peat formation in Belizean island forests. Journal of Ecology 89 (5), 818-828.

Moorhead, D. L., Sinsabaugh, R. L., 2006. A theoretical model of litter decay and microbial interaction. Ecological Monographs 76 (2), 151-174.

Naidoo, G., 2009. Differential effects of nitrogen and phosphorus enrichment on growth of dwarf Avicennia marina mangroves. Aquatic Botany 90 (2), $184-190$.

Neff, J. C., Townsend, A. R., Gleixner, G., Lehman, S. J., Turnbull, J., Bowman, W. D., 10 2002. Variable effects of nitrogen additions on the stability and turnover of soil carbon. Nature 419 (6910), 915-917. 
Nixon, S., 2009. Eutrophication and the macroscope. Hydrobiologia 629 (1), 5-19.

R Development Core Team, 2010. R: A Language and Environment for Statistical Computing. R Foundation for Statistical Computing, Vienna, Austria.

Reef, R., Feller, I. C., Lovelock, C. E., 2010. Nutrition of mangroves. Tree Physiology 30 (9), 1148-1160.

Robertson, A., 1988. Decomposition of mangrove leaf litter in tropical australia. Journal of Experimental Marine Biology and Ecology 116 (3), 235 $-247$.

Seitzinger, S. P., Mayorga, E., Bouwman, A. F., Kroeze, C., Beusen, A. H. W., Billen, G., Drecht, G. V., Dumont, E., Fekete, B. M., Garnier, J., Harrison, J. A., 2010. Global river nutrient export: A scenario analysis of past and future trends. Global Biogeochemical Cycles 24 (GB0A08).

Sessegolo, G. C., Lana, P. C., 1991. Decomposition of Rhizophora mangle, Avicennia schaueriana and Laguncularia racemosa leaves in a mangrove of Paranaguá Bay (southeastern Brazil). Botanica Marina 34 (4), 285-290.

Shaver, G. R., Giblin, A. E., Nadelhoffer, K. J., Thieler, K. K., Downs, M. R., Laundre, J. A., Rastetter, E. B., 2006. Carbon turnover in alaskan tundra soils: Effects of organic matter quality, temperature, moisture and fertilizer. Journal of Ecology 94 (4), 740-753.

Simkins, S., Alexander, M., 1984. Models for mineralization kinetics with the 
variables of substrate concentration and population density. Applied and Environmental Microbiology 47 (6), 1299-1306.

Tam, N. F. Y., Wong, Y. S., Wong, M. H., 2009. Novel technology in pollutant removal at source and bioremediation. Ocean and Coastal Management $52(7), 368-373$.

Torres, I., Inglett, K., Reddy, K., 2011. Heterotrophic microbial activity in lake sediments: effects of organic electron donors. Biogeochemistry 104, $165-181$.

Vance, E. D., Brookes, P. C., Jenkinson, D. S., 1987. An extraction method for measuring soil microbial biomass C. Soil Biology and Biochemistry 19 (6), 703-707.

Vrede, K., Heldal, M., Norland, S., Bratbak, G., 2002. Elemental composition $(\mathrm{C}, \mathrm{N}, \mathrm{P})$ and cell volume of exponentially growing and nutrient-limited bacterioplankton. Applied And Environmental Microbiology 68 (6), 29652971.

Wong, Y., Tam, N., Lan, C., Sep. 1997. Mangrove wetlands as wastewater treatment facility: a field trial. Hydrobiologia 352 (1), 49-59.

Yamasaki, A., Tateno, R., Shibata, H., 2011. Effects of carbon and nitrogen amendment on soil carbon and nitrogen mineralization in volcanic immature soil in southern Kyushu, Japan. Journal of Forest Research 16 (5), $414-423$. 


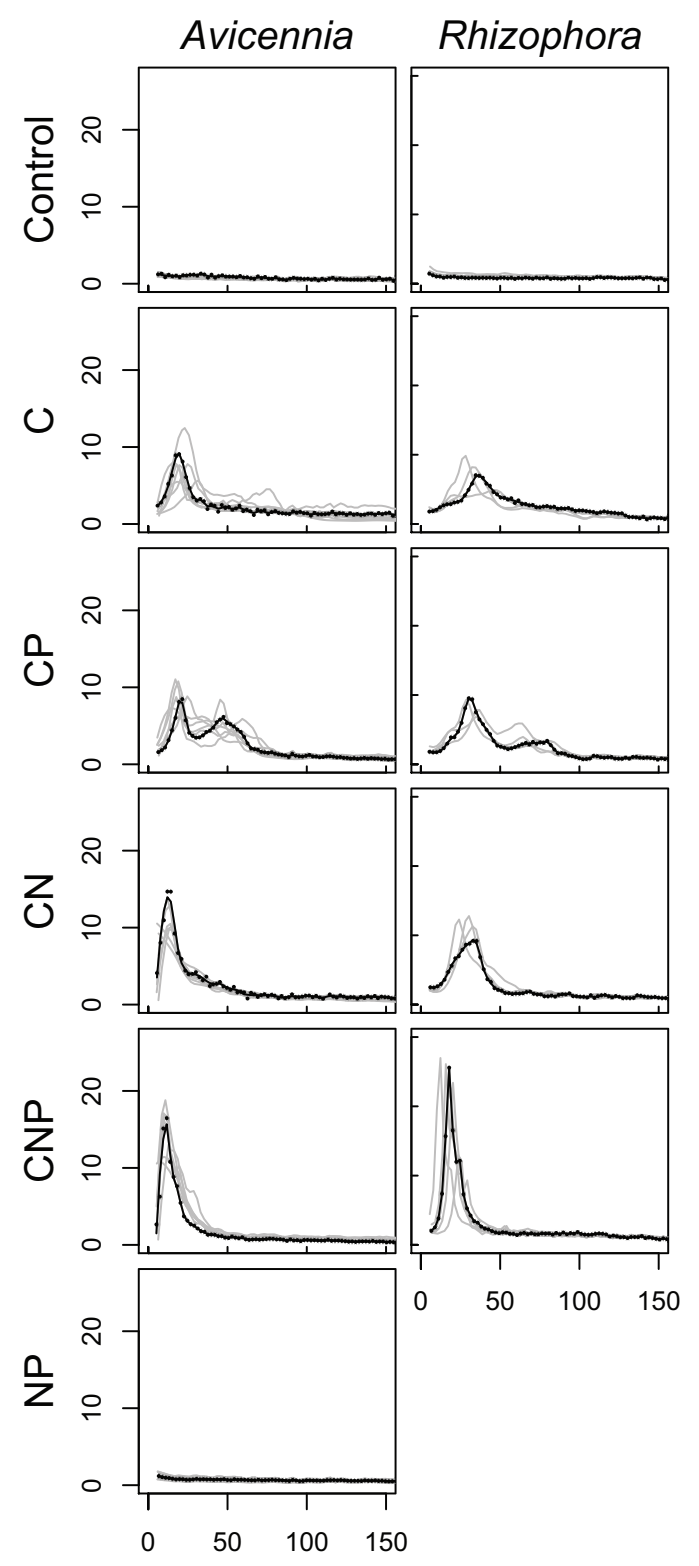

Figure 1: Respiration responses ( $\mathrm{gg} \mathrm{CO}_{2}-\mathrm{Ch}^{-1}$ ) in time (h) of soils from Avicennia marina and Rhizophora mucronata dominated sites in the Red Sea after amendment of $0.6 \mathrm{mg}$ glucose- $\mathrm{Cg}$ soil $\mathrm{FW}^{-1}(\mathrm{C})$, ammonium $(\mathrm{N})$ and/or phosphorus $(\mathrm{P})$ at $t=0 . \mathrm{CO}_{2}$ concentrations are measured every 2 hours. In each panel, one of the five to eight replicates is plotted in black with its measured values shown as black dots. 

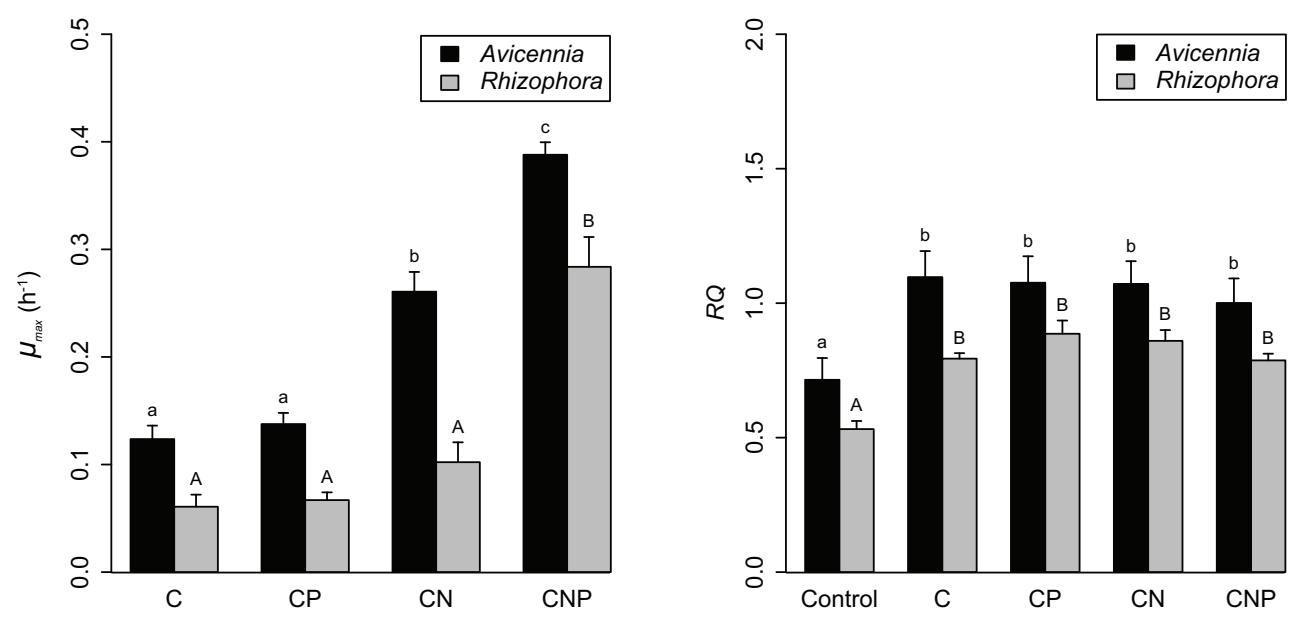

Figure 2: a) Microbial growth rate response and b) microbial respiratory quotient $R Q$ $\left(\mathrm{CO}_{2} / \mathrm{O}_{2}\right)$ of soils from Avicennia marina (black bars) and Rhizophora mucronata (grey bars) dominated sites in the Red Sea. Responses are measured after amendment with $0.6 \mathrm{mg}$ glucose-Cg soil $\mathrm{FW}^{-1}(\mathrm{C})$ in combination with ammonium (N) and/or phosphorus (P). Bars represent standard errors. Letters indicate differences between bars. All differences indicated are significant at $\mathrm{p}<0.001$, differences between species are significant at $\mathrm{p}<0.001$ in panel a and $\mathrm{p}<0.05$ in panel $\mathrm{b}$ 

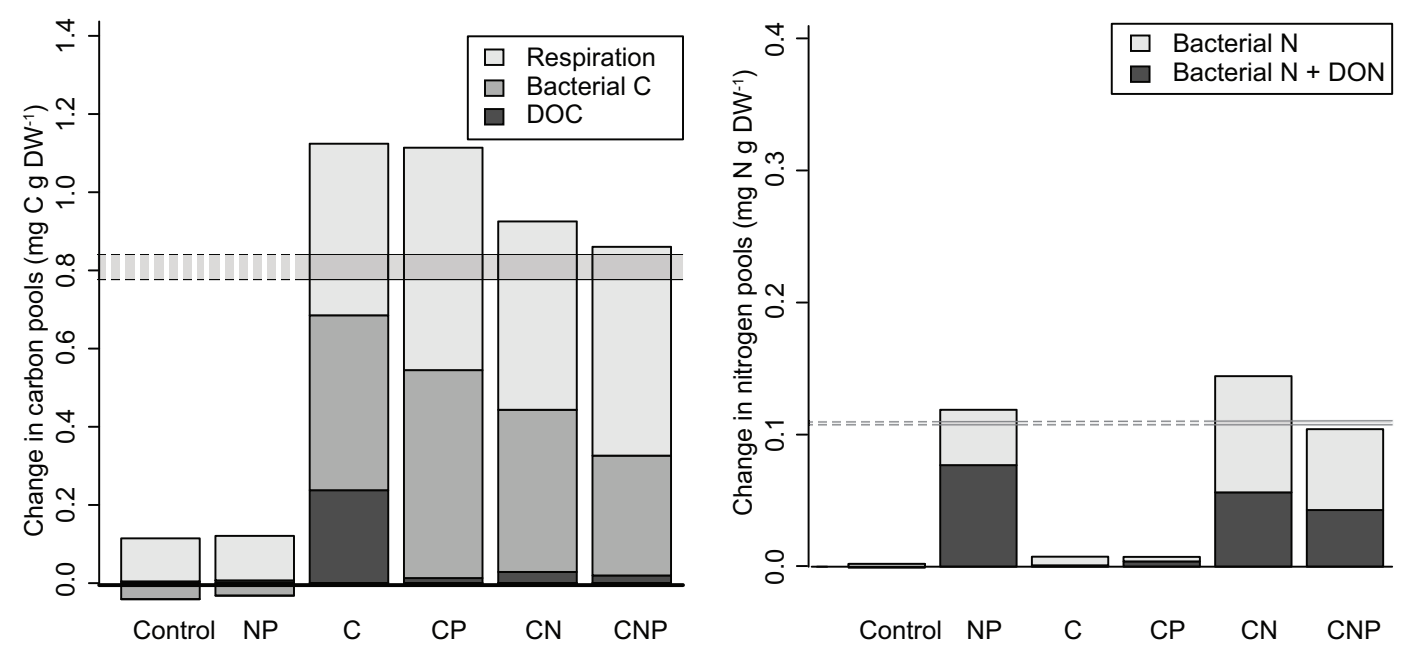

Figure 3: Total carbon (a) and nitrogen (b) budgets of soils from Avicennia marina dominated sites after $80 \mathrm{~h}$ of incubation. Soils were enriched with glucose (C), phosphorus $(\mathrm{P})$ and ammonium $(\mathrm{N})$ in various combinations. The horizontal bar shows the effect of amendment of $\mathrm{C}(\mathrm{a})$ or $\mathrm{N}$ (b) on the total budget. The lower border of this bar represents the direct effect of amendment; the height of the bar is the net budget change in the control treatment. $\mathrm{N}$ lowered total carbon mineralisation significantly compared with the $\mathrm{C}$ and CP treatments $(\mathrm{p}<0.05$, panel a). 


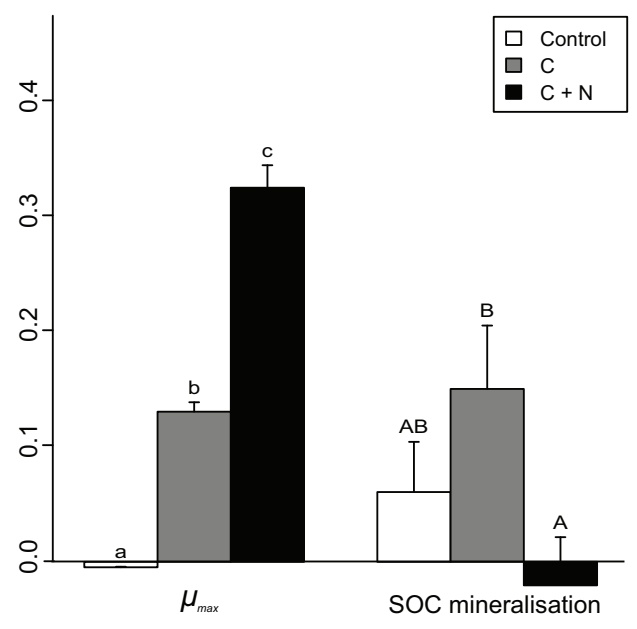

Figure 4: Relative microbial growth rates $\mu_{\max }\left(\mathrm{h}^{-1}\right)$ and net SOC mineralisation $\left(\mathrm{mgg}\right.$ soil $\mathrm{DW}^{-1}$ ) of soils from Avicennia marina dominated sites receiving $0.06 \mathrm{mg} g$ soil $\mathrm{FW}^{-1}$ of glucose in the $\mathrm{C}$ treatments and $0.06 \mathrm{\mu gg}$ soil $\mathrm{FW}^{-1}$ of nitrogen in the $\mathrm{N}$ treatments. Significance was tested using ANOVA for C and N within C, letters indicate significant differences at $\mathrm{p}<0.05$. 